University of Nebraska - Lincoln

DigitalCommons@University of Nebraska - Lincoln

$10-1-2021$

\title{
Validation of high-resolution melting assays for the detection of virulent strains of Escherichia coli 026 and 0111 in beef and pork enrichment broths
}

\author{
Frank J. Velez \\ Florida State University \\ Joseph M. Bosilevac \\ USDA-ARS, mick.bosilevac@ars.usda.gov \\ Prashant Singh \\ Florida State University, psingh2@fsu.edu
}

Follow this and additional works at: https://digitalcommons.unl.edu/hruskareports

Part of the Beef Science Commons, and the Meat Science Commons

Velez, Frank J.; Bosilevac, Joseph M.; and Singh, Prashant, "Validation of high-resolution melting assays for the detection of virulent strains of Escherichia coli 026 and 0111 in beef and pork enrichment broths" (2021). Roman L. Hruska U.S. Meat Animal Research Center. 534.

https://digitalcommons.unl.edu/hruskareports/534

This Article is brought to you for free and open access by the U.S. Department of Agriculture: Agricultural Research Service, Lincoln, Nebraska at DigitalCommons@University of Nebraska - Lincoln. It has been accepted for inclusion in Roman L. Hruska U.S. Meat Animal Research Center by an authorized administrator of DigitalCommons@University of Nebraska - Lincoln. 
Short communication

\title{
Validation of high-resolution melting assays for the detection of virulent strains of Escherichia coli $\mathrm{O} 26$ and $\mathrm{O} 111$ in beef and pork enrichment broths
}

\author{
Frank J. Velez ${ }^{\text {a }}$, Joseph M. Bosilevac ${ }^{\mathrm{b}}$, Prashant Singh ${ }^{\mathrm{a}}$, \\ ${ }^{\text {a }}$ Department of Nutrition, Food and Exercise Science, Florida State University, Tallahassee, FL, USA \\ ${ }^{\mathrm{b}}$ U.S. Department of Agriculture, Agricultural Research Service, Roman L. Hruska U.S. Meat Animal Research Center, Clay Center, NE, USA
}

\section{A R T I C L E I N F O}

\section{Keywords:}

Adulterants

Red meat

Real-time PCR

Shiga toxin-producing Escherichia coli (STEC)

\begin{abstract}
A B S T R A C T
Extensive validation of diagnostic assays using widely collected surveillance samples is critical for developing pathogen detection assays. The detection of potentially virulent $E$. coli strains is critical to the red meat industry. We previously developed two high-resolution melting (HRM) assays for detecting potentially virulent and avirulent $E$. coli $\mathrm{O} 26$ and 0111 strains. Assays were validated using enriched beef $(\mathrm{n}=36)$ and pork $(\mathrm{n}=36)$ samples collected as part of a U.S. federal regulatory surveillance program. Data from this study showed more than $90 \%$ sensitivity and specificity for both the HRM assays, demonstrating suitability for the red meat industry and regulatory agencies.
\end{abstract}

\section{Introduction}

Shiga toxin-producing Escherichia coli (STEC) are foodborne pathogens of great concern. In the United States, E. coli O157:H7 and six nonO157 STEC serogroups (i.e., O26, O45, O103, O111, O121, and O145) are considered adulterants in non-intact beef. The Centers for Disease Control and Prevention (CDC) National outbreak reporting system (NORS) for the year 2018 reported a total of 1228 illnesses, 293 hospitalization, and nine deaths, which were associated with STEC strains. Further, in 2019, the United States Department of Agriculture (USDA) Food Safety and Inspection Service (FSIS) initiated seven recalls due to the presence of STEC, which resulted in the recall of 298,500 pounds of food (USDA, FSIS, 2019). These recalled foods were comprised of raw ground beef, raw beef products, non-intact beef, and meat and poultry salad (USDA, FSIS, 2019).

The United States gross income from red meat sales (i.e., cattle, calves, hogs, and pigs) in 2019 was totaled at $\$ 88.7$ billion (USDA, 2020). The presence of STEC strains in raw non-intact beef products has been extensively documented in the past. However, only limited studies have been published on the presence of STEC in finished pork products (Bardasi et al., 2017; Scott et al., 2020). The food industry, especially the red meat industry, is constantly threatened by outbreaks associated with STEC serogroups. Contamination by STEC and recalls such as these can significantly impact the United States gross income from red meat sales (i.e., cattle, calves, hogs, and pigs).
The virulent strains of STEC serogroups possess the Shiga toxin gene $(s t x)$ and the adherence factor intimin (eae) gene. These two genes are considered essential for causing severe human infection. Human infection by a virulent STEC strain may result in acute illness, bloody diarrhea, hemorrhagic uremic syndrome, and renal failure (Majowicz et al., 2014). E. coli strains lacking these genes can be considered avirulent as far as causing bloody diarrhea and severe complications of the enterohemorrhagic disease. E. coli belonging to the seven adulterant STEC serogroups are comprised of both virulent and avirulent strains. That is, many isolates are positive for the serogroup. However, they lack the eae and $s t x$ virulence genes. Various virulent (or potentially virulent) and avirulent strains of $E$. coli serogroups are an integral part of cattle microbiota. These serogroups may contaminate the carcasses during animal slaughter and carcass processing (Brichta-Harhay et al., 2008; Nastasijevic et al., 2020). Real-time PCR-based 5'-nuclease assays are commonly used to test STEC serogroups present in food samples (Singh et al., 2019; Singh \& Mustapha, 2015). The USDA, FSIS describes the detection of STEC serogroups by initially screening for the presence of $s t x$ and eae genes. Samples testing positive for these two genes are then screened for the presence of E. coli O157:H7 and six non-O157 STEC serogroups using three sets of multiplex $5^{\prime}$-nuclease assays (USDA FSIS, 2020). A major limitation of this official method and other commercially available $5^{\prime}$-nuclease assays for STEC testing is that they may result in the diversion of meat products to thermal lethality steps due to the presence of avirulent strains of $E$. coli serogroups (i.e., false-positive test

\footnotetext{
* Corresponding author. Dept. of Nutrition, Food, and Exercise Sciences, Florida State University, 120 Convocation Way, Tallahassee, FL, 32306, USA

E-mail address: psingh2@fsu.edu (P. Singh).
} 
result). According to a USDA, FSIS Office of Public Health Science 2018 report, the false positive rates of potential screening were $93 \%$ for beef manufacturing trimming, $81 \%$ for ground beef, $100 \%$ for bench trim, and $94 \%$ for other components (USDA, FSIS, 2020b). This high false-positive rate results in an annual loss of approximately $\$ 47$ million for the beef industry (USDA, FSIS, 2020b).

This study aimed to validate our previously standardized two highresolution melting (HRM) assays. These two assays targeted SNPs on the serogroup-specific fnl1 and $w b d k$ genes for $\mathrm{O} 26$ and O111, respectively (Singh et al., 2020). The HRM assays can identify the presence of specific SNP associated with potentially virulent or avirulent strains. During HRM analysis, each gene variant generates a unique melt profile facilitating discrimination of isolates into potentially virulent or avirulent groups. Spiked food sample studies are often performed in controlled conditions, which is different from surveillance samples. Therefore, this study aimed to perform robust validation of our assays using DNA isolated from beef and pork enrichments obtained from the U.S. federal regulatory surveillance program (USFRSP).

\section{Methods}

\subsection{Samples}

DNA from 12 pure culture $E$. coli $\mathrm{O} 26$ strains (O26-2, O26-1, O26-3, O26-16.2, O26-699.1, O26 766.1, O26-859.3, O26-946.1, O26DEC10B, O26-97-3250, O26-MT\#10, and O26-TB352A) and 14 pure culture E. coli O111 strains (O111-hSTEC 08, O111-C4-462-2_7095, O111-F-A 790.1, O111 739.3, O111-7075, O111-F6627, O111-0201 9611, O111-3007-85 O111-LF1, O111-LF2, O111-LF3, O111-LF4, O111-LF5 and O111-LF6) were used (Table 1). The assay was validated using selected naturally contaminated beef $(n=36)$ and pork $(n=$ 36) enrichment samples, which were obtained from official testing laboratories (Supplementary Tables 1 and 2), which were processed according to the USDA FSIS MLG Chapter 5c. A portion of the initial enrichment broth was stripped of identity, mixed with glycerol (final concentration $17 \%$ ) and frozen at $-20{ }^{\circ} \mathrm{C}$, then shipped to the Meat Safety and Quality Research Unit laboratory for testing. The frozen broths were thawed, processed for STEC isolation according to FSIS MLG Chp 5c, and a separate portion was used for bacterial DNA isolation

Table 1

List of pure culture strains used as a control for validation of HRM assays.

\begin{tabular}{lll}
\hline Strains & $s t x$ & eae \\
\hline E. coli O26-2 & 1 & 1 \\
E. coli O26-1 & 1 & 1 \\
E. coli O26-3 & 1 & 1 \\
E. coli O26-16.2 & 0 & 0 \\
E. coli O26-699.1 & 0 & 1 \\
E. coli O26-766.1 & 0 & 0 \\
E. coli O26-859.3 & 0 & 0 \\
E. coli O26-946.1 & 0 & 0 \\
E. coli O26-DEC10B & 1 & 1 \\
E. coli O26-97-3250 & 1 & 1 \\
E. coli O26-MT\#10 & 1 & 1 \\
E. coli O26-TB352A & 1 & 1 \\
E. coli O111-hSTEC 08 & 0 & 1 \\
E. coli O111-C4-462-2_7095 & 1 & 1 \\
E. coli O111-F-A 790.1 & 0 & 1 \\
E. coli O111 739.3 & 0 & 0 \\
E. coli O111-7075 & 1 & 0 \\
E. coli O111-F6627 & 1 & 1 \\
E. coli O111-0201 9611 & 1 & 1 \\
E. coli O111-3007-85 & 1 & 1 \\
E. coli O111-LF1 & 0 & 0 \\
E. coli O111-LF2 & 0 & 0 \\
E. coli O111-LF3 & 0 & 0 \\
E. coli O111-LF4 & 0 & 0 \\
E. coli O111-LF5 & 0 & 0 \\
E. coli O111-LF6 & 0 & \\
\hline
\end{tabular}

using the Bacterial Genomic DNA Isolation Kit (Norgen, Biotek Corp, Ontario, Canada) following the manufacturer's recommendations. Samples that tested positive by the iQ-Check STEC VirX and SerO PCR Detection Kits (Bio-Rad Laboratories, Hercules, CA) were processed for the culture isolation of the specific serogroup of STEC identified following the method described in the USDA FSIS MLG Chapter 5c. Obtained isolates were characterized for the presence of virulence genes as described previously (Paton \& Paton, 1998). DNA isolated from the enrichments was shipped to Florida State University, Food Microbiology laboratory to validate HRM assays. The DNA samples were quantified using a Nanodrop One Spectrophotometer (Thermo Fisher, DE, USA). Samples were diluted to $10 \mathrm{ng} / \mu \mathrm{l}$ and used for the real-time PCR HRM assays.

\subsection{Oligonucleotides}

The oligonucleotides for this study were commercially synthesized and purchased from Integrated DNA Technologies (IDT, IA, USA). The E. coli $\mathrm{O} 26$ strains in the samples were detected by amplifying a fragment of serogroup specific frl 1 gene using O26-32F: 5'-GTG GCA CTG GTT CTT TTG GT-3' and O26-118R: $5^{\prime}$-TTT CAT CCC TGC TAA ATA TTC G-3' (Singh et al., 2020). Whereas the E. coli O111 strains were detected by amplifying the $w b d \mathrm{~K}$ gene using O111-634F: $5^{\prime}$-CTT CGA GCT CAT GGT TGG AC-3' and O111-717R: 5'-CGA CTC TTC GAA AAT ATC ATC A-3' primer-pair (Singh et al., 2020).

\subsection{High-resolution real-time PCR assay}

The PCR assays were performed on the LightCycler LC96 system (Roche Diagnostics, IN, USA) using $2 \times$ LightCycler ${ }^{\circledR} 480$ High Resolution melting master (Roche Diagnostics, IN, USA). The PCR assays were performed as previously described (Singh et al., 2020). Each $10 \mu \mathrm{l}$ PCR reaction consisted of $20 \mathrm{ng}$ of DNA, $2.5 \mathrm{mM} \mathrm{MgCl}_{2}$, and $0.5 \mu \mathrm{M}$ of each primer. The PCR amplifications were performed using one initial denaturation step $\left(95{ }^{\circ} \mathrm{C}\right.$ for $10 \mathrm{~min}$ ), followed by 40 cycles of denaturation at $95{ }^{\circ} \mathrm{C}$ for $15 \mathrm{~s}$ and annealing and extension at $62{ }^{\circ} \mathrm{C}$ for $30 \mathrm{~s}$. At the end of the amplification cycle, a high-resolution melt step was added. The amplification and high-resolution melt data were collected in Channel 1 (470/514 nm) of the LightCycler LC96 system. The HRM data for $\mathrm{O} 26$ amplicons were analyzed with a pre-melt and post-melt regions of $73.3-74.3^{\circ} \mathrm{C}$ and $78.7-79.7{ }^{\circ} \mathrm{C}$, respectively. Whereas the HRM data of $\mathrm{O} 111$ amplicons were analyzed with a pre-melt and post-melt regions of $71.5-72.5{ }^{\circ} \mathrm{C}$ and $78.2-79.2{ }^{\circ} \mathrm{C}$, respectively. Samples testing negative by the assay were removed from the HRM analysis.

\subsection{Sequencing}

The DNA samples testing positive by only the O26 and O111 HRM assays were confirmed by Sanger sequencing. The PCR amplicons generated using the above-mentioned primers pairs were purified using sodium acetate and ethanol precipitation (Sambrook \& Russell, 2006). Each purified amplicon was diluted to a $10 \mathrm{ng} / \mu$ l concentration. Samples were sequenced using $3.2 \mu \mathrm{M}$ of forward primer at Florida State University molecular cloning facility (Tallahassee, FL, USA). Obtained sequence chromatograms were edited using Chromas Lite v2.1.1 (Technelysium, Brisbane, Australia). Obtained sequence data was used for serogroup confirmation after BLAST analysis.

\subsection{Data analysis}

The sensitivity, specificity, false-positive (FP) rate, false negative (FN) rate, positive predictive value (PPV), negative predictive value (NPV), and test accuracy were calculated as previously described (Bosilevac et al., 2019). Assays showing sensitivity, specificity, positive predictive value, negative predictive, and test accuracy value greater 
than $90 \%$ were considered suitable for diagnostic applications (USDA, FSIS, 2010).

\section{Results}

Out of 72 enriched beef and pork samples tested in this study using our O26 HRM assay, a total of 16 were positive for the presence of O26. Twelve of these 16 samples correlated with the USDA FSIS MLG Bio-Rad SerO assay, while four were positive only by the HRM assay (Supplementary Tables 1 and 2). The four samples testing only by the O26 HRM assay and had a melting peak associated with potentially avirulent STEC-O26 strains, and these strains were further confirmed by Sanger sequencing. Therefore, these four samples were classified as true positive. The standardized $\mathrm{O} 26 \mathrm{HRM}$ assay for the serogroup identification showed sensitivity (100.0\%), specificity $(100.0 \%)$, FP rate $(0 \%)$, FN rate (0.0\%), PPV (100\%), NPV (100.0\%) and test accuracy (98.8\%). Based on HRM analysis, all 16 samples from beef and pork enrichments that tested positive by the O26 HRM assay grouped with the avirulent control strains (Fig. 1 A and B). Further, investigation of these samples showed they could not be culture-confirmed to possess an adulterant SETC-O26 strain.

The O111 HRM assay was previously validated using DNA from a limited set of E. coli $\mathrm{O} 111$ strains. Therefore, we expanded that validation here to a total of 14 pure culture $E$. coli 0111 strains. Five were the previously characterized strains used as positive controls, and six were recently isolated 0111 strains lacking $s t x$ and eae genes (O111-LF1, O111-LF2, O111-LF3, O111-LF4, O111-LF5, and O111-LF6). During the HRM analysis, the six new avirulent strains and 7075 strain (stx positive and eae negative) clustered with other previously identified avirulent E. coli 0111 strains. In contrast, the three STEC-O111 strains (i.e., F6627, 0201 9611, and 3007-85) clustered with potentially virulent strains.

Among 72 beef and pork enrichments, only 12 pork broths tested positive for the presence of O111 serogroup (Supplementary Tables 1 and 2). However, only four broths were identified as positive for $E$. coli O111 by the MLG method. Due to this, the O111 HRM assay, when compared with results generated using the MLG Chp $5 \mathrm{c}$ method, iQCheck STEC SerO PCR Detection Kit (Bio-Rad Laboratories, Hercules, CA), showed a false-positive rate of $10.5 \%$. All samples generating falsepositive results $(\mathrm{n}=8)$ using the HRM assay had a specific melt peak of $76.2{ }^{\circ} \mathrm{C}$, and after HRM analysis, the eight samples grouped with melt profiles of avirulent strains. The amplicons generated by these disagreeing samples $(n=8)$ were further verified by Sanger sequencing. Sequencing data confirmed the amplicons were indeed the expected E. coli $\mathrm{O} 111$ sequence and had not been identified by the official method (i.e., iQ-Check STEC SerO PCR Detection assay). Therefore, the eight samples were considered as true positive for further analysis. As such, the O111 HRM assay showed sensitivity (100\%), specificity (100\%), FP rate $(0 \%), \mathrm{FN}$ rate $(0 \%), \mathrm{PPV}(100 \%)$, NPV (100.0\%) and test accuracy
(100\%).

During HRM analysis, the 120111 positive pork enrichments and O111 control samples grouped into four distinct groups. The potentially virulent 0111 strain C4-462-2_7095 (stx positive and eae positive) grouped slightly apart $\left(\mathrm{Tm}: 75.6{ }^{\circ} \mathrm{C}\right.$ ) from other potentially virulent strains that possessed stx and eae. Whereas strains LF-2 and LF-3 formed a slightly distinct group compared $\left(\mathrm{Tm}: 76.8{ }^{\circ} \mathrm{C}\right)$ to other avirulent strains (Tm: 76.5) (Fig. 1 C and D). Culture confirmation of all 12 broth samples showed a lack of an adulterant 0111 strain.

\section{Discussion}

In addition to the culture-based method for pathogen isolation, diagnostic laboratories worldwide are moving towards cultureindependent diagnostic tests (CIDTs) for pathogen detection (CDC, 2019). Real-time PCR-based detection methods are recommended and commonly used for STEC detection. Multiple real-time PCR chemistries (e.g., intercalating dye, dual-labeled probe) are primarily used for the real-time detection of amplified products. Currently, USDA, FSIS method (i.e., MLG5) uses a combination of 9 primer pairs and nine dual-labeled probes to detect seven STEC serogroups. One of the major limitations of the FSIS official method (i.e., MLG5c) and other commercially available assays for detecting non-O157 STEC is their inability to distinguish avirulent from virulent strains in a single reaction. These standard and commercially available methods commonly rely on stx and eae gene multiplex assay for the screen of potentially positive broths. Multiple E. coli serogroups, Hafnia alvei, Citrobacter freundii, Shigella, and temperate phages are known to possess stx genes (Margot et al., 2013; Quirós et al., 2015).

Additionally, the intimin gene has been reported among Campylobacter, Citrobacter, Escherichia, and Shigella genera (Gassama et al., 2001; Hyma et al., 2005). Therefore, screening based on the stx and eae gene results in higher potentially positive broths (Bosilevac \& Koohmaraie, 2012). Between 2014 and 2020, the USDA FSIS tested 18,339 beef samples and among them identified 1008 as potentially positive following STEC screening (stx + eae + O-group + ). Out of the 1008 positive samples, STEC was confirmed only in 114 samples (Dr. J. Emilio Esteban, USDA, FSIS, personal communication, 2020). The difference of 894 samples (or $89 \%$ ) that could not be confirmed was most likely due to the detection of interfering non-pathogenic strains of top 6 STEC serogroups by the commercial assays. Further, when these sorts of broths are identified by beef producers as part of their process verification testing, the samples with avirulent strains result in product diversion and economic losses. In cases where a processor does not manufacture frozen products, the time required for culture confirmation is critical. Further, a screen positive product still cannot be released into commerce due to the difficulties of proving the screen result was the product of a mixed culture rather than a true positive.

In this study, a total of four and eight enrichments tested positive for
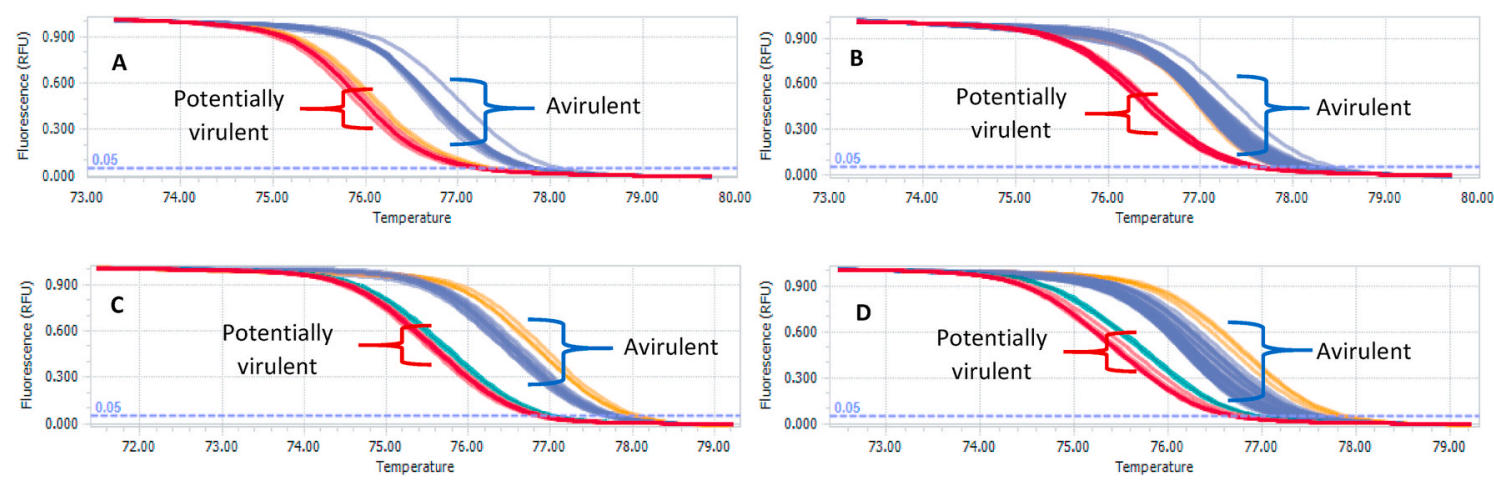

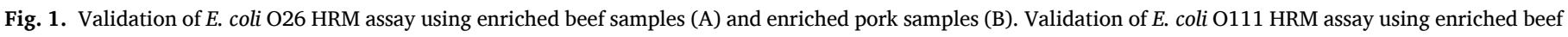
samples (C) and enriched pork samples (D). 
the presence of $\mathrm{O} 26$ and 0111 , respectively, only by the developed HRM assays (Supplementary Tables 1 and 2), which were further confirmed by Sanger sequencing of the amplicons. The observed variation between the developed HRM assays and the iQ-Check STEC SerO PCR Detection assay can be due to variations in primer binding site used for developing an assay, primer amplification efficiency, assay chemistry, or reaction conditions. Commercially available STEC serogroup detection assays rely on three to four target multiplex PCR reactions, which can result in competition in the PCR reaction resulting in lower PCR amplification efficiency. On the contrary, the HRM is always performed in a singleplex format, avoiding any reaction competition.

The O26 HRM assay gave mixed results for three pork enrichment broths. First, a false negative result, upon retesting by the O26 HRM assay, gave a positive result with a high $\mathrm{Cq}$ value $(\mathrm{Cq}=33-35)$. The DNA concentration of these three samples was quantified and retested to overrule the chances of any handling errors. We speculate that these three samples may be contaminated with low levels of O26, causing variation between repeated assays.

The pork enrichments showed a high positive rate for the E. coli $\mathrm{O} 26$ and 0111 strains. Similar results were reported for 465 not-ready-to-eat and 97 ready-to-eat pork products collected from the retail market and processing plants located in Italy. These samples were tested using ISO TS 13136:2012 method (Bardasi et al., 2017). Results from the study showed the presence of $E$. coli $\mathrm{O} 26$ and 0111 in $76.2 \%(\mathrm{n}=32 / 42)$ and $19 \%(n=8 / 42)$ of not-ready-to-eat samples, respectively (Bardasi et al., 2017). Despite the high PCR detection rate of STEC serogroups in pork samples collected from Italy, culture-based methods failed to isolate any STEC strain belong to the top seven STEC serogroups (Bardasi et al., 2017). Similar findings were reported by (Scott et al., 2020), which tested 1395 pork samples for STEC. Among these, 309 samples tested positive for the stx and eae genes and finely resulted in the isolation of only two adulterant STEC strains. These results demonstrate the high prevalence of potentially avirulent or non-viable STEC strains in the pork samples, which can interfere with testing and cause product diversion and loss of product value.

The $\mathrm{O} 26$ and O111 HRM assays validated using samples collected as part of a U.S. federal regulatory surveillance program provided sensitivity, specificity, positive predictive value, negative predictive, and test accuracy value greater than $90 \%$, which is recommended by the FSIS Guidance for test kit manufacturers (USDA, FSIS, 2010). Therefore, the two HRM assays can be considered suitable for diagnostic applications. The HRM assays that specifically detect the potentially virulent strains of STEC serogroups can substantially reduce the number and costs associated with the laborious multi-day process of culture confirmation of samples initially testing positive by molecular assays.

\section{Conclusion}

In conclusion, this study further validated our previously published STEC-O26 and STEC-O111 HRM assays using seventy-two enriched beef $(\mathrm{n}=36)$ and pork $(\mathrm{n}=36)$ broths. The $\mathrm{O} 26$ and O111 HRM assays are low-cost methods that distinguish between adulterant potentially virulent strains and avirulent background strains that interfere with current methods. Their use in standard practice will reduce the amounts of product diverted to lethality steps and increase the accuracy of regulatory monitoring for these adulterant STEC serogroups.

Supplementary Table 1

Data for beef enrichments.

\begin{tabular}{lllllll}
\hline Sl. No. & stx & eae & O26 USFRSP & O26 HRM & O111 USFRSP & O111 HRM \\
\hline 1 & 1 & 1 & 0 & 0 & 0 & 0 \\
2 & 1 & 1 & 0 & 0 & 0 & 0 \\
3 & 1 & 1 & 0 & 0 & 0 & 0 \\
4 & 1 & 1 & 0 & 0 & 0 & 0 \\
& & & & & & (continued on next column)
\end{tabular}

Supplementary Table 1 (continued)

\begin{tabular}{|c|c|c|c|c|c|c|}
\hline Sl. No. & $s t x$ & eae & O26 USFRSP & O26 HRM & O111 USFRSP & O111 HRM \\
\hline 5 & 1 & 0 & 0 & 0 & 0 & 0 \\
\hline 6 & 1 & 0 & 0 & 0 & 0 & 0 \\
\hline 7 & 1 & 0 & 0 & 0 & 0 & 0 \\
\hline 8 & 1 & 0 & 0 & 0 & 0 & 0 \\
\hline 9 & 1 & 0 & 0 & 0 & 0 & 0 \\
\hline 10 & 0 & 1 & 0 & 0 & 0 & 0 \\
\hline 11 & 1 & 0 & 0 & 0 & 0 & 0 \\
\hline 12 & 1 & 0 & 0 & 0 & 0 & 0 \\
\hline 13 & 1 & 1 & 0 & 0 & 0 & 0 \\
\hline 14 & 1 & 1 & 0 & 0 & 0 & 0 \\
\hline 15 & 1 & 0 & 0 & 0 & 0 & 0 \\
\hline 16 & 1 & 0 & 0 & 0 & 0 & 0 \\
\hline 17 & 1 & 0 & 0 & 0 & 0 & 0 \\
\hline 18 & 1 & 0 & 0 & 0 & 0 & 0 \\
\hline 19 & 0 & 1 & 0 & 0 & 0 & 0 \\
\hline 20 & 1 & 1 & 1 & 1 & 0 & 0 \\
\hline 21 & 1 & 1 & 0 & 0 & 0 & 0 \\
\hline 22 & 1 & 0 & 0 & 0 & 0 & 0 \\
\hline 23 & 1 & 0 & 0 & 0 & 0 & 0 \\
\hline 24 & 0 & 1 & 0 & 0 & 0 & 0 \\
\hline 25 & 1 & 0 & 0 & 0 & 0 & 0 \\
\hline 26 & 0 & 1 & 0 & 0 & 0 & 0 \\
\hline 27 & 1 & 1 & 0 & 0 & 0 & 0 \\
\hline 28 & 0 & 1 & 0 & 0 & 0 & 0 \\
\hline 29 & 1 & 1 & 0 & 0 & 0 & 0 \\
\hline 30 & 1 & 1 & 0 & 0 & 0 & 0 \\
\hline 31 & 0 & 1 & 0 & 0 & 0 & 0 \\
\hline 32 & 0 & 1 & 0 & 0 & 0 & 0 \\
\hline 33 & 0 & 1 & 0 & 0 & 0 & 0 \\
\hline 34 & 0 & 1 & 0 & 0 & 0 & 0 \\
\hline 35 & 1 & 1 & 0 & 0 & 0 & 0 \\
\hline 36 & 1 & 1 & 0 & 0 & 0 & 0 \\
\hline
\end{tabular}

DNA samples at the FSIS laboratory were tested for the presence of stx and eae genes using Biorad VirX. Samples for the presence of STEC serogroups were tested using the BioRad sero O screening assay and O26 and O111 HRM assays standardized by (Singh et al., 2020). The $\mathrm{O} 26$ and 0111 USFRSP represent the data test results provided by the USDA. The O26 and 0111 HRM represent the results from the assay developed in our study. In the table, " 0 " represents

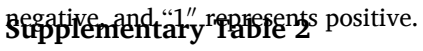

Data for pork enrichments.

\begin{tabular}{|c|c|c|c|c|c|c|}
\hline Sl. No. & stx & eae & O26 USFRSP & O26 HRM & O111 USFRSP & O111 HRM \\
\hline 1 & 1 & 1 & 0 & 0 & 0 & 0 \\
\hline 2 & 1 & 1 & 1 & 1 & 0 & 1 \\
\hline 3 & 1 & 1 & 0 & 0 & 0 & 0 \\
\hline 4 & 1 & 1 & 0 & 0 & 1 & 1 \\
\hline 5 & 1 & 1 & 1 & 0 & 0 & 0 \\
\hline 6 & 1 & 1 & 1 & 1 & 0 & 1 \\
\hline 7 & 1 & 1 & 0 & 0 & 0 & 0 \\
\hline 8 & 1 & 1 & 1 & 1 & 0 & 0 \\
\hline 9 & 1 & 1 & 1 & 1 & 0 & 0 \\
\hline 10 & 1 & 1 & 1 & 0 & 0 & 0 \\
\hline 11 & 1 & 1 & 0 & 1 & 0 & 1 \\
\hline 12 & 1 & 1 & 0 & 1 & 0 & 0 \\
\hline 13 & 1 & 1 & 0 & 0 & 0 & 1 \\
\hline 14 & 1 & 1 & 1 & 1 & 0 & 1 \\
\hline 15 & 1 & 1 & 1 & 1 & 0 & 0 \\
\hline 16 & 1 & 1 & 0 & 0 & 0 & 0 \\
\hline 17 & 1 & 1 & 0 & 0 & 0 & 1 \\
\hline 18 & 1 & 1 & 0 & 0 & 1 & 1 \\
\hline 19 & 1 & 1 & 0 & 0 & 0 & 0 \\
\hline 20 & 1 & 1 & 0 & 1 & 0 & 0 \\
\hline 21 & 1 & 1 & 1 & 1 & 0 & 0 \\
\hline 22 & 1 & 1 & 0 & 0 & 0 & 0 \\
\hline 23 & 1 & 1 & 1 & 1 & 0 & 0 \\
\hline 24 & 1 & 1 & 0 & 0 & 0 & 0 \\
\hline 25 & 1 & 1 & 0 & 0 & 0 & 0 \\
\hline 26 & 1 & 1 & 1 & 1 & 0 & 1 \\
\hline 27 & 1 & 1 & 0 & 0 & 0 & 0 \\
\hline 28 & 1 & 1 & 0 & 0 & 0 & 0 \\
\hline 29 & 1 & 1 & 0 & 0 & 0 & 0 \\
\hline 30 & 1 & 1 & 1 & 0 & 0 & 0 \\
\hline 31 & 1 & 1 & 0 & 0 & 0 & 0 \\
\hline
\end{tabular}


Supplementary Table 2 (continued)

\begin{tabular}{lllllll}
\hline Sl. No. & stx & eae & O26 USFRSP & O26 HRM & O111 USFRSP & O111 HRM \\
\hline 32 & 1 & 1 & 0 & 1 & 0 & 1 \\
33 & 1 & 1 & 0 & 0 & 0 & 0 \\
34 & 1 & 1 & 1 & 1 & 1 & 1 \\
35 & 1 & 1 & 1 & 1 & 1 & 1 \\
36 & 1 & 1 & 0 & 0 & 0 & 0 \\
\hline
\end{tabular}

DNA samples at the FSIS laboratory were tested for the presence of stx and eae genes using Biorad VirX. Samples for the presence of STEC serogroups were tested using the BioRad sero O screening assay and O26 and O111 HRM assays standardized by (Singh et al., 2020). The O26 and O111 USFRSP represent the data test results provided by the USDA. The O26 and O111 HRM represent the results from the assay developed in our study. In the table, " 0 " represents negative, and " 1 " represents positive.

\section{CRediT authorship contribution statement}

Frank J. Velez: Investigation. Joseph M. Bosilevac: Resources, Writing - review \& editing. Prashant Singh: Conceptualization, Methodology, Validation, Data curation, Writing - original draft, Supervision, Project administration.

\section{Acknowledgments}

This study was funded by Florida State University startup funds and Grant Assistance Program (GAP) Commercialization Investment Program funds awarded to the Dr. Prashant Singh. Product names are necessary to report factually on available data; however, their mentioning by a USDA author neither guarantees nor warrants the standard of the product, and the use of the name implies no approval of the product to the exclusion of others that may also be suitable. The USDA is an equal opportunity provider and employer.

\section{References}

Bardasi, L., Taddei, R., Fiocchi, I., Pelliconi, M. F., Ramini, M., Toschi, E., \& Merialdi, G. (2017). Shiga toxin-producing Escherichia coli in slaughtered pigs and pork products. Italian Journal of Food Safety, 6(2), 79-82. https://doi.org/10.4081/ijfs.2017.6584

Bosilevac, J. M., Dwivedi, H. P., Chablain, P., Ullery, M., Bailey, J. S., \& Dutta, V. (2019). Comparative performance evaluation of real-time PCR and dual-labeled fluorescence resonance energy transfer probe-based melt peak analysis for the detection of Escherichia coli O157:H7 in beef products. Journal of Food Protection, 82(3), 507-512. https://doi.org/10.4315/0362-028X.JFP-18-366

Bosilevac, J. M., \& Koohmaraie, M. (2012). Predicting the presence of non-O157 Shiga toxin-producing Escherichia coli in ground beef by using molecular tests for Shiga toxins, intimin, and O serogroups. Applied and Environmental Microbiology, 78(19), 7152-7155. https://doi.org/10.1128/AEM.01508-12

Brichta-Harhay, D. M., Guerini, M. N., Arthur, T. M., Bosilevac, J. M., Kalchayanand, N., Shackelford, S. D., Wheeler, T. L., \& Koohmaraie, M. (2008). Salmonella and Escherichia coli O157:H7 contamination on hides and carcasses of cull cattle presented for slaughter in the United States: An evaluation of prevalence and bacterial loads by immunomagnetic separation and direct plating methods. Applied and Environmental Microbiology, 74(20), 6289-6297. https://doi.org/10.1128/ AEM.00700-08

Centers for Disease Control and Prevention (CDC). (2019). Culture-independent diagnostic tests | food safety | CDC. November 4, Retrieved from https://www.cdc. gov/foodsafety/challenges/cidt.html. (Accessed 9 March 2021).

Gassama, A., Sow, P. S., Fall, F., Camara, P., Philippe, H., Guèye-N'diaye, A., Seng, R., Samb, B., M'Boup, S., Germani, Y., \& Aïdara-Kane, A. (2001). Ordinary and opportunistic enteropathogens associated with diarrhea in senegalese adults in relation to human immunodeficiency virus serostatus. International Journal of Infectious Diseases, 5(4), 192-198. https://doi.org/10.1016/S1201-9712(01)90069-4

Hyma, K. E., Lacher, D. W., Nelson, A. M., Bumbaugh, A. C., Janda, J. M., Strockbine, N. A., Young, V. B., \& Whittam, T. S. (2005). Evolutionary genetics of a new pathogenic Escherichia species: Escherichia albertii and related Shigella boydii strains. Journal of Bacteriology, 187(2), 619-628. https://doi.org/10.1128/ JB.187.2.619-628.2005

Majowicz, S. E., Scallan, E., Jones-Bitton, A., Sargeant, J. M., Stapleton, J., Angulo, F. J., Yeung, D. H., \& Kirk, M. D. (2014). Global incidence of human Shiga toxin-producing Escherichia coli infections and deaths: A systematic review and knowledge synthesis. Foodborne Pathogens and Disease, 11(6), 447-455. https://doi. org/10.1089/fpd.2013.1704

Margot, H., Cernela, N., Iversen, C., Zweifel, C., \& Stephan, R. (2013). Evaluation of seven different commercially available real-time PCR assays for detection of Shiga toxin 1 and 2 gene subtypes. Journal of Food Protection, 76(5), 871-873. https://doi. org/10.4315/0362-028X.JFP-12-365

Nastasijevic, I., Schmidt, J. W., Boskovic, M., Glisic, M., Kalchayanand, N., Shackelford, S. D., Wheeler, T. L., Koohmaraie, M., \& Bosilevac, J. M. (2020). Seasonal prevalence of Shiga toxin-producing Escherichia coli on pork carcasses for three steps of the harvest process at two commercial processing plants in the United States. Applied and Environmental Microbiology, 87(1), e01711-e01720. https://doi. org/10.1128/AEM.01711-20

Paton, A. W., \& Paton, J. C. (1998). Detection and characterization of Shiga toxigenic Escherichia coli by using multiplex PCR assays for stx 1, stx 2, eaeA, Enterohemorrhagic E. coli hlyA, rfb O111, and rfb O157. Journal of Clinical Microbiology, 36(2), 598-602. https://doi.org/10.1128/JCM.36.2.598-602.1998

Quirós, P., Martínez-Castillo, A., \& Muniesa, M. (2015). Improving detection of Shiga toxin-producing Escherichia coli by molecular methods by reducing the interference of free Shiga toxin-encoding bacteriophages. Applied and Environmental Microbiology, 81(1), 415-421. https://doi.org/10.1128/AEM.02941-14

Sambrook, J., \& Russell, D. W. (2006). Standard ethanol precipitation of DNA in microcentrifuge tubes. Cold Spring Harbour Protocols, 2006(1). https://doi.org/ 10.1101/pdb.prot4456. June 1.

Scott, M. E., Mbandi, E., Buchanan, S., Abdelmajid, N., Gonzalez-Rivera, C., Hale, K. R., Jacobsen, L., Webb, J., Green, J., \& Dolan, P. (2020). Salmonella and Shiga toxin-producing Escherichia coli in products sampled in the food safety and inspection service raw pork baseline study. Journal of Food Protection, 83(3), 552-559. https://doi.org/10.4315/0362-028X.JFP-19-360

Singh, P., Cubillos, G., Kirshteyn, G., \& Bosilevac, J. M. (2020). High-resolution melting real-time PCR assays for detection of Escherichia coli O26 and O111 strains possessing Shiga toxin genes. LWT-Food Science and Technology, 131, Article 109785. https://doi.org/10.1016/j.lwt.2020.109785

Singh, P., Liu, Y., Bosilevac, J. M., \& Mustapha, A. (2019). Detection of Shiga toxinproducing Escherichia coli, stx1, stx2 and Salmonella by two high resolution melt curve multiplex real-time PCR. Food Control, 96, 251-259. https://doi.org/10.1016/ j.foodcont.2018.09.024

Singh, P., \& Mustapha, A. (2015). Multiplex real-time PCR assays for detection of eight Shiga toxin-producing Escherichia coli in food samples by melting curve analysis. International Journal of Food Microbiology, 215, 101-108. https://doi.org/10.1016/j. ijfoodmicro.2015.08.022

United States Department of Agriculture (USDA). (2020). Meat animals production, disposition, and income 2019 summary. Retrieved from https://downloads.usda. library.cornell.edu/usda-esmis/files/02870v85d/6m3127982/x920gh39g/meatan2 0 .pdf. (Accessed 9 March 2021).

United States Department of Agriculture (USDA), Food Safety Inspection Service (FSIS). (2010). FSIS guidance for test kit manufacturers, laboratories: Evaluating the performance of pathogen test kit methods. Retrieved from https://www.fsis.usda. gov/shared/PDF/Validation_Studies_Pathogen_Detection_Methods.pdf. (Accessed 9 March 2021).

United States Department of Agriculture (USDA), Food Safety Inspection Service (FSIS). (2019). Recall summaries 2018. Retrieved from https://www.fsis.usda.gov/wps/por tal/fsis/topics/recalls-and-public-health-alerts/recall-summaries. (Accessed 9 March 2021).

United States Department of Agriculture (USDA), Food Safety Inspection Service (FSIS). (2020a). Detection, isolation, and identification of top seven Shiga toxin-producing Escherichia coli (STECs) from meat products and carcass and environmental sponges. Retrieved from https://www.fsis.usda.gov/wps/wcm/connect/7ffc02 b5-3d33-4a79-b50c-81f208893204/mlg-5.pdf?MOD=AJPERES. (Accessed 9 March 2021).

United States Department of Agriculture (USDA), Food Safety Inspection Service (FSIS). (2020b). Expansion of FSIS Shiga toxin-producing Escherichia coli (STEC) testing to additional raw beef products. Federal Register, 34397-34402, 85 FR 34397; Docket No. FSIS-2010-0023, Retrieved from https://www.federalregister.gov/documents 2020/06/04/2020-12073/expansion-of-fsis-shiga-toxin-producing-escherichia-colistec-testing-to-additional-raw-beef. (Accessed 9 March 2021). 